\title{
Plant Electrophysiological Information Manifests the Composition and Nutrient Transport Characteristics of Membrane Protein
}

Cheng Zhang

Jiangsu University

Yanyou Wu ( $\nabla$ wuyanyou@mail.gyig.ac.cn )

Institute of Geochemistry Chinese Academy of Sciences https://orcid.org/0000-0002-0940-4349

Yue Su

Guizhou Vocatiional College of Agriculture

Deke Xing

Jiangsu University

Lei Fang

Institute of Geochemistry Chinese Academy of Sciences

Research

Keywords: electrophysiological information, bioenergetics, membrane protein composition, nutrient transport

Posted Date: September 9th, 2020

DOl: https://doi.org/10.21203/rs.3.rs-68762/v1

License: (c) (1) This work is licensed under a Creative Commons Attribution 4.0 International License. Read Full License 
1 Plant electrophysiological information manifests the composition and nutrient transport

2 characteristics of membrane protein

3

4 Cheng Zhang ${ }^{\mathrm{a}, \mathrm{b}}$, Yanyou $\mathrm{Wu}^{\mathrm{b}, \mathrm{a}^{*}}$, Yue $\mathrm{Su}^{\mathrm{c}}$, Deke Xing ${ }^{\mathrm{a}}$, Lei Fang ${ }^{\mathrm{b}}$

5

$6 \quad{ }^{a}$ Key Laboratory of Modern Agricultural Equipment and Technology, Ministry of Education, College of Agricultural 7 Equipment and Engineering, Jiangsu University, Zhenjiang 212013, China.

$8{ }^{\mathrm{b}}$ State Key Laboratory of Environmental Geochemistry, Institute of Geochemistry, Chinese Academy of Sciences, 9 Guiyang 550081, China.

${ }^{c}$ Guizhou Vocational College of Agriculture, Qingzhen 551400, China.

13 *Correspondence: Yanyou Wu, Email: wuyanyou@ @ail.gyig.ac.cn, Tel: +86 085184391746

14 The work was carried out at State Key Laboratory of Environmental Geochemistry, Institute of Geochemistry,

15 Chinese Academy of Sciences. 


\section{Plant electrophysiological information manifests the composition and nutrient transport}

characteristics of membrane protein

\section{Abstract}

Background: Almost all life activities of plants are accompanied by electrophysiological information. Plant electrical parameters are considered to be the fastest response to environment.

Results: In this study, the theoretically intrinsic relationships between the clamping force and leaf resistance (R), capacitive reactance $(\mathrm{Xc})$ and inductive reactance $(\mathrm{XL})$ were revealed as 3-parameter exponential decay based on bioenergetics for the first time. The intrinsic resistance (IR), intrinsic capacitive reactance (IXc) and intrinsic inductive reactance (IXL) in plant leaves were monitored via these relationships for the first time, and the nutrient transport capacity (NTC) in plant cells based on IR, IXc and IXL was first defined. The results indicate that IXc and IXL could be used to manifest the composition of surface and binding proteins in cell membrane, plant with high crude proteins and crude ash had higher NTC, and which accurately revealed the nutrient transport strategies in tested plants.

Conclusions: This study highlights that plant electrophysiological information could effectively manifest the composition and nutrient transport characteristics of membrane protein in plant cells.

Keywords: electrophysiological information, bioenergetics, membrane protein composition, nutrient transport . 
Almost all life activities in plants, including the metabolism of substances and energy, development, stress resistance and signal transduction, involve charge separation, electron movement, proton and dielectric transport, etc. [1-2]. The electrical properties of plant cells are derived from the cell membrane with a double electric layer, which is two electron density bands approximately $2.5 \mathrm{~nm}$ thick on the inside and outside of the membrane and a transparent band approximately $2.5 \mathrm{~nm}$ thick in the middle. And membrane lipids and proteins, the mainly compositions of cell membrane, can be regarded as insulating layer, have a high electrical resistivity, enabling the plant cell to store electric charge [3]. Therefore, the electrophysiological information in plants is closely related to the life activities, and the changes of structure, composition and ion permeability in plant cells will inevitably lead to significant changes in electrophysiological information [3-8].

Plant electrical parameters are considered to be the fastest response to environmental stimulus such as drought, salt stimulation, cold stimulation, diseases and insect pests, exogenous force [7-11]. Previously, a traditional approach, the electrical parameters in plants are measured by the insertion of two electrodes into the stem or leaf [12-13]. However, this method is unstabitily and difficult to manipulate, and the plant electrical signals acquired lacked representativeness, reproducibility and comparability needling injury, as well as different environments, users and other factors. Moreover, the intrinsic or spontaneous electrical parameters in plants are not detected by previously methods. Thus, can the intrinsic relationships between environmental stimulus and electrophysiological parameters be feasible to obtain intrinsic electrical parameters with high reproducibility in plants or evaluate their life phenomena? Can these intrinsic relationships be described by corresponding physical mechanism models?

Generally, a mesophyll cell can be regarded as a concentric sphere capacitor with both inductor and resistor function, and many aligned mesophyll cells make up the leaf capacitor [2, 14]. The ions, ion groups and electric dipoles in mesophyll cells are electrolytes of leaf capacitor and most related to electrophysiological information [15]. Interestingly, Guo et al. [16] reported the capacitance (C) values of maize leaves increased with clamping forces, and manifested clamping forces stimuli changed the electrophysiological information in plant leaves. However, this intrinsic mechanism or relationship between clamping force and the electrophysiological information of plant leaves wasn't revealed. Thus, it is of great practical significance to clarify the intrinsic mechanism between clamping forces and electrophysiological parameters and provide a rapid, accurate and real-time technique for monitoring the physiological state of plant leaves. 
Cell is the site of all biochemical reactions, and cell membrane side is an important barrier to ensure a stable environment inside the cell. It has been estimated that $15 \sim 30 \%$ of the nuclear gene encoded proteins are involved in nutrient transport on the cell membrane, and the energy used by cells in nutrient transport up to two-thirds of the total energy consumed by cells [1]. The nutrient transport capacity of cells is most closely related to the type and quantity of surface and binding proteins in cell membrane, thus, the composition and content of membrane protein can indirectly reflect the nutrient transport capacity of cells. Protein detection methods of biological samples include conventional, electrochemical, molecular biology, electrophoresis and mass spectrometry methods [17]. However, the detection of membrane proteins is limited to single cell or single proteins, and the existing protein detection technology is difficult to accurately evaluate the composition characteristic of cell membrane protein [17-18]. Moreover, the nutrient transport capacity ultimately affects the nutrient use efficiency of plants, and the most commonly used method of plant nutrient use evaluation is the ratio of total nutrient in plants to total input nutrient [19-20]. However, this nutrient use efficiency also does not directly reflect the nutrient transport capacity. To the best of our knowledge, the composition and nutrient transport characteristics of membrane protein has rarely been reported.

The fully expanded leaves, which account for a high proportion of plant biomass, determine and reflect the plant nutrient metabolism. Since the concentration of electrolytes in cells (ions, ion groups and electric dipoles) in leaf cells is directly affected by the nutrient metabolism in plant leaves, and then it is accompanied by vigorously electrical activities. In this study, it was first clarified and constructed the intrinsic mechanisms and physical models between clamping forces and leaf resistance (R), capacitive reactance (Xc) and inductive reactance (XL). Subsequently, the intrinsic electrophysiological parameters in plant leaves were monitored through these mechanism equations. And then the nutrient transport capacity (NTC) in plant leaves in the light of the intrinsic electrophysiological parameters was defined to evaluate the nutrient transport strategies of various tested plants. This study aims to clarify the intrinsic mechanisms among the leaf $\mathrm{R}, \mathrm{Xc}$ and $\mathrm{XL}$ and exogenous stimuli, and provide a novel, feasible technique for real-time monitoring plant nutrient transport .

\section{Results}

\section{Intrinsic mechanism relationships of clamping force (F) and leaf $R, X c$ and $X L$}


Almost all life activities in plants are closely related to the electrophysiological information. In a mesophyll cell, cell membrane has strict selective permeability to various ions, ion groups and electric dipoles, and the electrolyte solution on both sides of cell membrane forms a specific conductive state. The inside and outside of cell membrane can be simulated as a capacitor, the electrolyte solution on both sides of the membrane is equivalent to the two plates of the capacitor, and cell membrane is equivalent to intermediate medium of the capacitor. Moreover, organelles such as vacuoles and cytoplasm in cells are equivalent to resistors. Thus, mesophyll cell can be regarded as a concentric sphere capacitor with both inductor and resistor functions. The simplified equivalent circuit of mesophyll cell is displayed in Fig. 1.

\section{Fig. 1.}

Plant electrophysiological information obtained by the traditional needling method is often less authenticity, reproducibility and comparability due to needling injury, different environments and technicians, and other factors [11]. The ions, ion groups and electric dipoles in the plant leaf were used as electrolytes, and a parallel-plate capacitor sensor could be formed by placing the leaf between the two plates of the parallel-plate capacitor. The leaf R, $\mathrm{Xc}$ and $\mathrm{XL}$ varied with the ions, ion groups and electric dipoles concentrations in the plant leaf, and different clamping forces which can be regarded as different exogenous stimuli inevitably lead to changes the ions, ion groups and electric dipoles concentrations in plant leaves. To obtain authentic, comparable and reproducible plant electrophysiological data, the intrinsic mechanism models between the clamping force and leaf R, Xc and XL were revealed.

The concentration of the electrolytes determines inside and outside $\mathrm{R}$ of the cell membrane. External stimuli change the membrane permeability of the electrolytes and affect their inside and outside concentration of the cell membrane. Under different clamping forces, the membrane permeability of the electrolytes that respond to $\mathrm{R}$ in the plant cell membrane changed. According to the bioenergetics, the Nernst equation can be used to quantitatively describe the potential of electrolytes inside and outside of the cell membrane. Thus, the concentration differences in the electrolytes that respond to inside and outside $\mathrm{R}$ of the cell membrane obey the Nernst equation and can be expressed as follows:

$$
E-E^{0}=\frac{R_{0} T}{n_{R} F_{0}} \ln \frac{C_{i}}{C_{o}}
$$



$\left.\mathrm{K}^{-1} \mathrm{~mol}^{-1}\right), \mathrm{T}=$ the thermodynamic temperature $(\mathrm{K}), \mathrm{C}_{\mathrm{i}}=$ the concentration of the electrolytes that respond to $\mathrm{R}$ inside the cell membrane ( $\left.\mathrm{mol} \mathrm{L}^{-1}\right), \mathrm{C}_{\mathrm{o}}=$ the concentration of the electrolytes that respond to $\mathrm{R}$ outside the cell membrane $\left(\mathrm{mol} \mathrm{L}^{-1}\right), \mathrm{F}_{0}=$ Faraday constant $\left(96485 \mathrm{C} \mathrm{mol}^{-1}\right)$, and $\mathrm{n}_{\mathrm{R}}=$ the number of transferred electrolytes (mol).

The internal energy of the electromotive force can be converted into pressure work, and they have a direct relationship, $\mathrm{PV}=\mathrm{a} \mathrm{E}$, that is:

$$
P V=a E=a E^{0}+\frac{a R_{0} T}{n_{R} F_{0}} \ln \frac{Q_{i}}{Q_{0}}
$$

where $\mathrm{P}=$ the pressure intensity on the leaf cells $(\mathrm{Pa}), \mathrm{a}=$ the energy conversion coefficient of the electromotive force, and $\mathrm{V}=$ the cell volume $\left(\mathrm{m}^{3}\right) . \mathrm{P}=\frac{\mathrm{F}}{\mathrm{S}}$, where $\mathrm{F}=$ the clamping force $(\mathrm{N})$ and $\mathrm{S}=$ the effective area of the electrode plate $\left(\mathrm{m}^{2}\right)$. F can be calculated by the gravity formula:

$$
F=(M+m) g
$$

where $\mathrm{M}=$ the iron block mass $(\mathrm{kg}), \mathrm{m}=$ the mass of the plastic rod and the plate electrode $(\mathrm{kg})$, and $\mathrm{g}=9.8 \mathrm{~N} / \mathrm{kg}$.

For mesophyll cells, the sum of $\mathrm{C}_{\mathrm{o}}$ and $\mathrm{C}_{\mathrm{i}}$ is certain. $\mathrm{C}_{\mathrm{i}}$ is directly proportional to the conductivity of the electrolytes that respond to $R$, and the conductivity is the reciprocal of R. Hence, $\frac{C_{i}}{C_{o}}$ can be expressed as $\frac{C_{i}}{C_{o}}=$ $\frac{\frac{f_{0}}{R}}{C_{T}-\frac{f_{0}}{R}}=\frac{f_{0}}{C_{T} R-f_{0}}$, where $f_{0}=$ the ratio coefficient of the conversion between $C_{i}$ and $R$, and $C_{T}=C_{o}+C_{i}$. Therefore, formula (2) was transformed into formula (4):

$$
\frac{\mathrm{v}}{\mathrm{S}} \mathrm{F}=\mathrm{a} \mathrm{E}^{0}-\frac{\mathrm{a} \mathrm{R}_{0} \mathrm{~T}}{\mathrm{n}_{\mathrm{R}} \mathrm{F}_{0}} \ln \frac{\mathrm{C}_{\mathrm{T}} \mathrm{R}-\mathrm{f}_{0}}{\mathrm{f}_{0}}
$$

Formula (4) was rewritten:

and

$$
\frac{a R_{0} T}{n_{R} F_{0}} \ln \frac{C_{T} R-f_{0}}{f_{0}}=a E^{0}-\frac{v}{S} F
$$

Further: 
144 Because $\mathrm{d}=\frac{\mathrm{v}}{\mathrm{S}}$, formula (8) was transformed into:

$$
R=\frac{f_{0}}{C_{T}}+\frac{f_{0}}{C_{T}} e^{\frac{n_{R} F_{0} E^{0}}{R_{0} T}} e^{\left(-\frac{\mathrm{d} \mathrm{n}_{R} F_{0}}{a R_{0} T} F\right)}
$$

146 For the same leaf tested in the same environment, the $d, a, E^{0}, R_{0}, T, n_{R}, F_{0}, C_{T}$, and $f_{0}$ of formula (9) are constant.

147 Let $y_{0}=\frac{f_{0}}{C_{T}}, k_{1}=\frac{f_{0}}{C_{T}} e^{\frac{n_{R} F_{0} E^{0}}{R_{0} T}}, b_{1}=\frac{d_{R} F_{0}}{a R_{0} T}$, and the intrinsic mechanism relationships of leaf $R$ and $F$ was:

$$
\mathrm{R}=\mathrm{y}_{0}+\mathrm{k}_{1} e^{-\mathrm{b}_{1} \mathrm{~F}}
$$
where $\mathrm{y}_{0}, \mathrm{k}_{1}$ and $\mathrm{b}_{1}$ are model parameters. When $\mathrm{F}=0$, the intrinsic resistance (IR) of the plant leaves could be obtained:

$$
\mathrm{IR}=\mathrm{y}_{0}+\mathrm{k}_{1}
$$

With the same R, the intrinsic mechanism relationships of leaf Xc and F was revealed (Additional file 1):

$$
\mathrm{Xc}=\mathrm{p}_{0}+\mathrm{k}_{2} \mathrm{e}^{-\mathrm{b}_{2} \mathrm{~F}}
$$

When $\mathrm{F}=0$, the intrinsic capacitive reactance (IXc) of plant leaves could be calculated as:

$$
\mathrm{IXc}=\mathrm{p}_{0}+\mathrm{k}_{2}
$$
With the same R, the intrinsic mechanism relationships of leaf XL and F was revealed (Additional file 1): where $\mathrm{q}_{0}, \mathrm{k}_{3}$ and $\mathrm{b}_{3}$ are model parameters. When $\mathrm{F}=0$, the intrinsic inductive reactance (IXL) of plant leaves could be calculated as:

$$
\mathrm{IXL}=\mathrm{q}_{0}+\mathrm{k}_{3}
$$


The IR of the plant leaves is calculated according to formula (16):

$$
\frac{1}{\mathrm{IR}}=\frac{1}{\mathrm{IR}_{1}}+\frac{1}{\mathrm{IR}_{2}}+\frac{1}{\mathrm{IR}_{3}}+\ldots \frac{1}{\mathrm{IR}_{n}}
$$

It is assumed that the membrane inside and outside resistance of each cell is equal, then $\mathrm{IR}_{1}, \mathrm{IR}_{2}, \mathrm{IR}_{3}, \ldots \mathrm{IR}_{\mathrm{n}}$ can represent intrinsic resistance of each unit cell membrane. It is assumed that the intrinsic resistance of each cell membrane is equal, that is $I R_{1}=I R_{2}=I R_{3}=\ldots=I R_{n}=I R_{0}$. Thus, the IR of the plant leaves was obtained:

$$
\frac{1}{\mathrm{IR}}=\frac{\mathrm{n}}{\mathrm{IR}_{0}}
$$

Due to membrane resistance is most closely related to proteins and lipids of cell membrane, then $\mathrm{n}$ can be characterized as the amount of proteins and lipids that induce membrane resistance in plant leaves.

The IXc of the plant leaves is calculated according to formula (18):

$$
\frac{1}{\mathrm{IXc}}=\frac{1}{\mathrm{IXc}_{1}}+\frac{1}{\mathrm{IXc}_{2}}+\frac{1}{\mathrm{IXc}_{3}}+\ldots \frac{1}{\mathrm{IXc}_{\mathrm{p}}}
$$

It is assumed that the membrane inside and outside capacitive resistance of each cell is equal, then IXc $\mathrm{IXc}_{1}, \mathrm{IXc}_{3}$, $\ldots I X c_{p}$ can represent intrinsic capacitive resistance of each unit cell membrane. Similarly, it is assumed that the intrinsic capacitive resistance of each cell membrane is equal, that is $\mathrm{IXc}_{1}=\mathrm{IXc}_{2}=\mathrm{IXc}_{3}=\ldots=\mathrm{IXc}_{\mathrm{p}}=\mathrm{IXc}_{0}$. Thus, the IXc of the plant leaves was obtained:

$$
\frac{1}{\mathrm{IXc}}=\frac{\mathrm{p}}{\mathrm{IXc}_{0}}
$$

Due to membrane capacitive resistance is most closely related to surface proteins of cell membrane, then IXc or $\mathrm{p}$ can be characterized as the amount of surface proteins that induce membrane capacitive resistance in plant leaves. Clearly, IXc is inversely proportional to $\mathrm{p}$. The lower IXc, the more surface proteins.

The IXL of the plant leaves is calculated according to formula (20):

$$
\frac{1}{\mathrm{IXL}}=\frac{1}{\mathrm{IXL}_{1}}+\frac{1}{\mathrm{IXL}_{2}}+\frac{1}{\mathrm{IXL}_{3}}+\ldots \frac{1}{\mathrm{IXL}_{\mathrm{q}}}
$$
$\mathrm{IXL}_{3}, \ldots \mathrm{IXL}_{\mathrm{q}}$ can represent intrinsic inductive resistance of each unit cell membrane. Similarly, it is assumed that 
the intrinsic inductive resistance of each cell membrane is equal, that is $\mathrm{IXL}_{1}=\mathrm{IXL}_{2}=\mathrm{IXL}_{3}=\ldots=\mathrm{IXL}_{\mathrm{q}}=\mathrm{IXL}_{0}$. Thus, the IXL of the plant leaves was obtained:

$$
\frac{1}{\mathrm{IXL}}=\frac{\mathrm{q}}{\mathrm{IXL}_{0}}
$$

Due to membrane inductive resistance is most closely related to binding proteins of cell membrane, then IXL or q can be characterized as the amount of binding proteins that induce membrane inductive resistance in plant leaves. Same, IXL is inversely proportional to q. The lower IXL, the more binding proteins.

The cell membrane proteins are most closely related to the nutrient transport, thus, the nutrient transport capacity (NTC) could be represented by formula (22):

$$
\mathrm{NTC}=\frac{\mathrm{IXc}+\mathrm{IXL}}{\mathrm{IR}}
$$

\section{Electrophysiological information and nutrient transport of B. papyrifera grow in two habitats}

The fitting equation parameters of between clamping force and leaf $\mathrm{R}, \mathrm{Xc}$, and $\mathrm{XL}$ of B. papyrifera grown in agricultural and moderately rocky desertification soils are shown in Table 1, Fig. 2 randomly lists the fitting curves for 1-4 leaf of B. papyrifera in agricultural soil. The correlation coefficients $\left(R^{2}\right)$ of the fitting equations of R-F, Xc-F, and XL-F for nine leaves of B. papyrifera grown in agricultural and moderately rocky desertification soils were $0.9044 \sim 0.9929,0.9033 \sim 0.9910$ and $0.9085 \sim 0.9895$, and $0.9722 \sim 0.9976,0.9910 \sim 0.9986$ and $0.9862 \sim 0.9976$, respectively. Moreover, all the $P$ values of the fitting equation parameters were lower than 0.0001 . These results show that the relationships of between clamping force and leaf R, Xc, and XL display good correlations, and highlight that the intrinsic mechanism relationships of those are authentic existence.

\section{Table 1}

Fig. 2.

The intrinsic electrophysiological information and the nutrient transport capacity of $B$. papyrifera in two conditions were successful monitored using the corresponding equation parameters. As shown in Table 2, the leaf IR, 
IXc and IXL of B. papyrifera in the agricultural soil are significantly $(p<0.01)$ lower than those of that in the moderately rocky desertification soil. Theoretically, the lower IXc and IXL, the more surface and binding proteins.

214 Actually, crude protein of B. papyrifera in the agricultural soil are significant $(p<0.05)$ higher than those of that in the moderately rocky desertification soil, which is in good agreement with IXc and IXL. Moreover, for the same plant, the leaf IXc is lower than IXL which shows that binding proteins is more than surface proteins. As displayed in Table 2, the NTC and crude ash of B. papyrifera in the agricultural soil are significantly $(p<0.01)$ higher than those of that in the moderately rocky desertification soil. The results showed that B. papyrifera in the agricultural soil grow well under the high nutrient (crude ash) conditions, and cell membrane proteins (crude protein) were relatively much which supported it higher NTC as compared to that in the moderately rocky desertification soil.

Table 2

Electrophysiological information and nutrient transport of the herbaceous and woody plants

As illustrated in Table 3, the IR, IXc and IXL of different plants are obviously different, the IXc is lower than IXL in same plant. For the same species plants in the same growth habitat, the NTC, crude protein and crude ash of $R$. chinensis are significantly $(p<0.01)$ higher than those of T. sinensis, and those of I. batatas were significantly $(p<$ 0.05) higher than those of S. scandens. The results showed that the higher crude protein and crude ash in same species plants, the higher NTC.

Table 3

\section{Electrophysiological information and nutrient transport of S. tuberosum and C. annuum}

As shown in Table 4, the leaf IR, IXc and IXL of S. tuberosum are significantly $(p<0.01)$ lower than those of $C$. annuum in the same growth habitat, while NTC, crude protein and crude ash are higher. And IXc is lower than IXL in same plant. The results showed that $S$. tuberosum with high membrane protein (crude protein) and nutrient (crude ash) contents promote the efficient transport and utilization of nutrients by its membrane proteins, which made it had higher nutrient transport capacity (NTC). 


\section{Discussion}

Almost all life activities in plants involve charge separation, electron movement, proton and dielectric transport, etc. In mesophyll cells, cells and organelles are both surrounded by the cell membrane composed of $50 \%$ lipids, $40 \%$ proteins and 2 10\% sugars [1-2]. Membrane lipids and membrane proteins can be regarded as insulating layer, have a high electrical resistivity, enabling the plant cell to store electric charge [3]. Surface (or peripheral) proteins account for $20 \sim 30 \%$ of membrane proteins, bind to lipids on both sides of the membrane with charged amino acids or groups, and binding (or intrinsic) proteins account for $70 \sim 80 \%$ of membrane proteins, bind to lipids through hydrophobic hydroxyl groups in the membrane [1-2]. Surface proteins affect the capacitive reactance and capacitance, while binding proteins affect the inductive reactance and inductance. Therefore, the mesophyll cells can be regarded as a concentric sphere capacitor with both inductor and resistor function, and the ions, ion groups and electric dipoles are equivalent to electrolytes of capacitor [2, 14-15].

When plant leaves are subjected to clamping force stimuli (or environmental stresses), the cell membrane permeability of leaves changes instantly, and then the concentration of the ions, ion groups and electric dipoles inevitably changes, resulting in the changes of the leaf R, Xc and XL. Nernst equation can quantitatively describe the potential formed by ions between systems A and B, and it can theoretically also be used to quantitatively describe the diffusion potential of the electrolytes inside and outside of the cell membrane. Based on this fact, the R, Xc or XL $=\mathrm{y}+\mathrm{k} e^{-\mathrm{bF}}$ of the theoretically intrinsic relationships between clamping force and leaf $\mathrm{R}, \mathrm{Xc}$ or XL were revealed for the first time. The results show that the relationships of between clamping force and leaf R, Xc, and XL displayed good correlations, and highlight that the aforementioned intrinsic mechanism are authentic existence. Generally, the intrinsic or spontaneous electrophysiological information in plants are not detectable [11]. In this study, the IR, IXc and IXL of plant leaves were successfully obtained via the theoretically intrinsic relationships between clamping force and leaf R, Xc and XL for the first time, which overcome the lack of representativeness, stability and reproducibility of the traditional needing approach. 
in this study showed that IXc and IXL could be used to manifest the composition of surface and binding proteins in cell membrane, that was, the lower IXc and IXL, the more surface and binding proteins. This is closely related to the fact that the high content of membrane proteins promoted the nutrient elements to pass through cell membrane more smoothly, thus made the cell membrane resistivity lower. In this study, plant with high crude proteins had relatively lower IR, IXc and IXL, which strongly supported the feasibility of using IXc and IXL to characterize the composition characteristic of membrane proteins. This study found that a phenomenon was common in the all tested plants, that was, the IXc was lower than IXL in same plant. This result perfectly proves the life fact that binding proteins is more than surface proteins in cell membrane [1-2].

Due to the poor nutritional environments, plants in rocky desertification soils are more vulnerable to low nutrient stress than those in cultivated soils [22-24]. The results showed that B. papyrifera in the agricultural soil grow well under the high nutrient (or crude ash) conditions, and cell membrane protein (or crude protein) content were higher which supported it higher nutrient transport capacity as compared to that in the moderately rocky desertification soil. The monitoring of the transport capacity of plant nutrients has rarely been reported in previous studies. In this study, the nutrient transport capacity (NTC) was defined based on IR, IXc and IXL for the first time. The results showed that the higher crude protein and crude ash in all tested plants, the higher NTC. The possible reason is that plant with high membrane protein (crude protein) and nutrient (crude ash) contents promoted the efficient transport and utilization of nutrients by its membrane proteins, which made it had well nutrient transport capacity. Overall, NTC commendably reflected the nutrient transport strategies in various tested plant, and could monitor the nutrient transport status of plants in real time. Additionally, the novel nutrient parameter were obtained by the intrinsic electrophysiological information in plants, which had well authenticity, stability, comparability and reproducibility. This study highlights that IR, IXc and IXL of plant electrophysiological information could effectively manifest the composition and nutrient transport characteristics of membrane protein in plant cells.

\section{Conclusion}

The present work provided a novel method based on plant electrophysiological information for accurately manifest the composition and nutrient transport characteristics of membrane protein in plant cells. The theoretically intrinsic relationships among the leaf $\mathrm{R}, \mathrm{Xc}, \mathrm{XL}$ and clamping force were first revealed on the basis of Nernst equation, and the IR, IXc and IXL of the intrinsic electrophysiological parameters in plant leaves were monitored via 
these relationships for the first time and used to manifest the composition characteristic of cell membrane proteins. NTC was firstly defined based on IR, IXc and IXL which accurately revealed and reflected the nutrient transport strategies in tested plants.

\section{Materials and methods}

\section{Experimental materials}

The two Broussonetia papyrifera grown in the agricultural and moderate rocky desertification soil in Puding county, Guizhou Province $\left(26^{\circ} 37^{\prime} \mathrm{N}, 105^{\circ} 77^{\prime}\right.$ E). Rhus chinensis Mill. and Toona sinensis grown in the moderate rocky desertification soil in Puding county, and Ipomoea batatas (L.) Lam. and Senecio scandens Buch.-Ham. ex D. grown in the cultivated soil in Puding county. Solanum tuberosum L. and Capsicum annuum L. were grown in the potted agricultural soil of Guizhou vocational college of agriculture in Qingzhen county, Guizhou Province $\left(26^{\circ} 58^{\prime}\right.$ N, $106^{\circ} 43^{\prime}$ E). The average annual temperature, sunshine hours and precipitation in Puding and Qingzhen counties were 15.1 and $14.1^{\circ} \mathrm{C}, 1164.9$ and 1128.2 hours and 1378.2 and $1180.9 \mathrm{~mm}$, respectively. The growth age, habitat information, measurement conditions and sampling weather of all tested plants are shown in Table 5. The fully expanded leaves of fresh branch as experimental materials were measured. First, the fully expanded leaves were taken from the third, fourth, and fifth leaf positions of each branch, and the fresh leaves were immediately soaked in water for $30 \mathrm{~min}$. Then, the water on the surface of the leaves was removed. Three branches of each plant were measured. The tested leaves were sampled and measured at $8 \sim 10$ a.m. on sunny days, and the measurement temperature was room temperature $\left(25.0 \pm 2.0{ }^{\circ} \mathrm{C}\right)$.

Table 5

\section{Leaf electrophysiological parameters and crude ash measurement}

The fully expanded leaves from the third, fourth, and fifth leaf positions of three branches in plants were measured. 

frequency and voltage of $3 \mathrm{kHz}$ and $1.5 \mathrm{~V}$, respectively, as described by Zhang et al. [24]. Every mesophyll cell can be regarded as a concentric sphere capacitor, many aligned mesophyll cells make up the leaf capacitor, the parallel connection modes of LCR is thus applied. Firstly, the leaf was put between the two electrodes of a self-made parallel-plate capacitor with a diameter of $7 \mathrm{~mm}$ (Fig. 3). And then leaf capacitance (C), impedance (Z) and R at different clamping forces were continuously collected by adding the same quality iron blocks, and recorded 11-13 data each clamping force. Finally, leaf Xc and XL were respectively obtained according to formula (23) and (24):

\section{Data analyses}

The data were analyzed using SPSS 18.0 (SPSS Inc., Chicago, IL, USA). A one-way analysis of variance followed by Duncan's test was performed.

\section{List of abbreviations}

C: capacitance, Z: impedance, R: resistance, Xc: capacitive reactance, XL: inductive reactance, IR: intrinsic resistance, IXc: intrinsic capacitive reactance, IXL: intrinsic inductive reactance, NTC: nutrient transport capacity. 
Supplementary information accompanies this paper at

Additional file 1. Construction of the relationship models of clamping force (F) and leaf Xc, XL.

Additional file 2. Raw data

Ethics approval and consent to participate

Not applicable.

\section{Consent for publication}

Not applicable.

The datasets generated and/or analysed during the current study are available in in this published article and its supplementary information files.

\section{Competing interests}

The authors declare that they have no conflicts of interest.

\section{Funding}

367 We thank the National Natural Science Foundation of China (No. U1612441-2), the Key Technologies Research and 368 Development Program of China (No. 2016YFC0502607-02, 2016YFC0502602-5), the Science and technology innovation talent project of Guizhou Province [No. (2015)4035], and the scientific and technological achievement 


\section{Authors' contributions}

YYW constructed conception. YYW and CZ designed research. CZ, YS and LF performed research. CZ and DX analyzed data. CZ and YYW wrote the paper. All authors read and approved the final manuscript.

\section{Acknowledgements}

377

\section{Author details}

${ }^{1}$ Key Laboratory of Modern Agricultural Equipment and Technology, Ministry of Education, College of Agricultural Equipment and Engineering, Jiangsu University, Zhenjiang 212013, China; ${ }^{2}$ State Key Laboratory of Environmental Geochemistry, Institute of Geochemistry, Chinese Academy of Sciences, Guiyang 550081, China; ${ }^{3}$ Guizhou Vocational College of Agriculture, Qingzhen 551400, China

\section{References}

1. Hopkins WG, Huner NPA. Introduction to Plant Physiology. 3rd ed. New York: John Wiley \& Sons Inc. 2004 ; p. 27.

2. Volkov AG. Plant Electrophysiology: Theory and Methods. Springer. 2006.

3. Yan X, Wang Z, Huang L, Wang C, Hou R, Xu Z, Qiao X. Research progress on electrical signals in higher plants. Progr. Nat. Sci. Mater. Int. 2009; 19: 531-541.

4. Choi WG, Hilleary R, Swanson SJ, Kim SH, Gilroy S. Rapid, long-distance electrical and calcium signaling in 
5. Nguyen CT, Kurenda A, Stolz S, Chetelat A, Farmer EE. Identification of cell populations necessary for leaf-to-leaf electrical signaling in a wounded plant. Proc. Natl. Acad. Sci. U. S. A. 2018; 115: 10178-10183.

6. Hedrich R, Salvador-Recatala V, Dreyer I. Electrical wiring and long-distance plant communication. Trends Plant Sci. 2016; 21: 376-387.

7. Gil PM, Gurovich L, Schaffer B, Alcayaga J, Rey S, Iturriaga R. Root to leaf electrical signaling in avocado in response to light and soil water content. J. Plant Physiol. 2008; 165: 1070-1078.

8. Favre P, Greppin H, Agosti RD. Accession-dependent action potentials in Arabidopsis. J. Plant Physiol. 2011; 168: $653-660$.

9. Gallé A, Lautner S, Flexas J, Fromm J. Environmental stimuli and physiological responses: The current view on electrical signaling. Environ Exp Bot, 2015; 114: 15-21.

10. Macedo FCO, Dziubinska H, Trebacz K, Oliveira RF, Moral RA. Action potentials in abscisic acid-deficient tomato mutant generated spontaneously and evoked by electrical stimulation. Acta Physiol. Plant. 2015; 37.

11. Wang ZY, Qin XH, Li JH, Fan LF, Zhou Q, Wang YQ, Zhao X, Xie CJ, Wang ZY, Huang L. Highly reproducible periodic electrical potential changes associated with salt tolerance in wheat plants. Environ Exp Bot, 2019; 160:

12. Chen Y, Zhao DJ, Wang ZY, Wang ZY, Tang G, Huang L. Plant electrical signal classification based on waveform similarity. Algorithms. 2016; 9: 1-23.

13. Zhao DJ, Wang ZY, Li J, Wen X, Liu A, Wang XD, Hou RF, Wang C, Huang L. Recording extracellular signals

15. Philip N. Biological Physics: Energy, Information Life. New York: Freeman and Company. 2003; p.413-448.

16. Guo WC, Liu DX, Zhou CC, Han WT. Non-destructive moisture detector for plant leaves based on capacitance. 
17. Zhang AM, Wang R, Xie H, Xie XH, Shi YQ, Jia ZP, Sun K. Summarization on the methodology study of protein detection. Letters in Biotechnology. 2011; 22(01): 130-134. (in Chinese)

18. Li L, Wang Q, Feng J, Tong LL, Tang B. Highly sensitive and homogeneous detection of membrane protein on a single living cell by aptamer and nicking enzyme assisted signal amplification based on microfluidic droplets. Anal Chem, 2014; 86(10):5101-5107.

19. Borges BMMN, Strauss M, Camelo PA, Sohi SP, Franco HCJ. Re-use of sugarcane residue as a novel biochar fertiliser - Increased phosphorus use efficiency and plant yield. J. Clean. Prod, 2020; 262: 121406.

20. Geng YJ, Chen L, Yang C, Jiao DY, Zhang YH, Cai ZQ. Dry-season deficit irrigation increases agricultural water use efficiency at the expense of yield and agronomic nutrient use efficiency of Sacha Inchi plants in a tropical humid monsoon area. Industrial Crops \& Products, 2017; 109: 570-578.

21. Wen XQ, Shu YG, He H. Soil nutrients and microbial characteristics under different land utilization patterns in Karst mountainous area. Southwest China Journal of Agricultural Sciences, 2018; 31(6): 1227-1233. (in Chinese)

22. Wu YY, Xing DK, Hang HT, Zhao K. Principles and Technology of Determination on Plant' Adaptation to Karst Environment. Beijing: Science Press. 2019; p.191-191.

23. Xing DK, Chen XL, Wu YY, Xu XJ, Chen Q, Li Lin, Zhang C. Rapid prediction of the re-watering time point of Orychophragmus violaceus L. based on the online monitoring of electrophysiological indexes. Sci Hortic-Amsterdam. 2019; 256: 108642.

24. Zhang MM, Wu YY, Xing DK, Zhao K, Yu R. Rapid measurement of drought resistance in plants based on electrophysiological properties. Transactions of the ASABE, 2015; 58(6): 1441-1446.

25. Rayees B, Dorcus M, Chitra S. Nutritional composition and oil fatty acids of Indian winter melon Benincasa hispida (Thunb.) seeds. Int. Food Res. J, 2013; 20(3): 1151-1155. 


\section{$441 \quad$ Figure captions}

442 Fig. 1. Simplified equivalent circuit of cells. $Z=$ impedance, $C_{m}=$ capacitance of membrane, $R_{m}=$ resistance of 443 membrane, $\mathrm{Xc}_{\mathrm{m}}=$ capacitive reactance of membrane, $\mathrm{XL}_{\mathrm{m}}=$ inductive reactance of membrane, $\mathrm{R}_{\mathrm{o}}=$ resistance of 444 membrane outside, $\mathrm{R}_{\mathrm{i}}=$ resistance of membrane inside

445 Fig. 2. Fitting equations of the relationship between R (a), Xc (b), XL (c) of the fourth expanded leaf of the first 446 branch of B. papyrifera grown in the agricultural soils and champing force $(\mathrm{F})$

447 Fig. 3. The experimental setup used in the study and a schematic diagram of the parallel-plate capacitor. $1=$ holder

448 (315 $\mathrm{mm}$ of height), $2=$ cystosepiment $(32 \mathrm{~mm}$ of diameter $), 3=$ plate electrode $(7 \mathrm{~mm}$ of diameter $), 4=$ electrical 449 conductor, $5=$ iron block, $6=$ plastic $\operatorname{rod}(295 \mathrm{~mm}$ of height $), 7=$ bench holdfast $(130 \mathrm{~mm}$ of length $)$.

\section{$451 \quad$ Table captions}

452 Table 1 The fitting equation parameters of B. papyrifera in two habitats

Table 2 The nutrient transport parameters of B. papyrifera in two habitats

Table 3 The nutrient transport parameters of four plants

Table 4 The nutrient transport parameters of $S$. tuberosum and C. annuum

Table 5 Growth age, habitat information, measuring conditions and sampling weather of all tested plants 


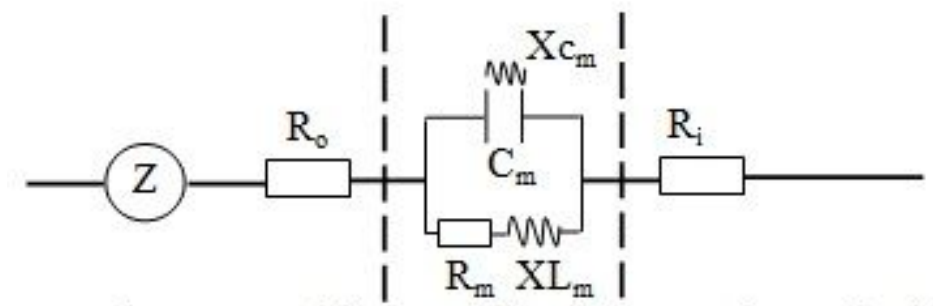

Membrane outside I Membrane I Membrane inside

\section{Figure 1}

Simplified equivalent circuit of cells. $\mathrm{Z}=$ impedance, $\mathrm{Cm}=$ capacitance of membrane, $\mathrm{Rm}=$ resistance of membrane, $\mathrm{Xcm}=$ capacitive reactance of membrane, $\mathrm{XLm}=$ inductive reactance of membrane, $\mathrm{Ro}=$ resistance of membrane outside, $\mathrm{Ri}=$ resistance of membrane inside
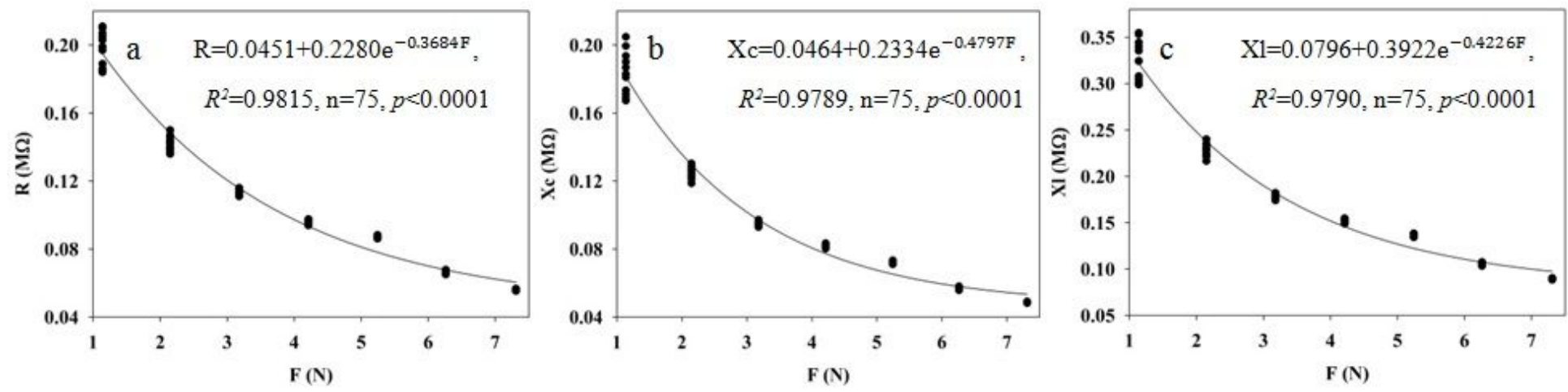

Figure 2

Fitting equations of the relationship between $R(a), X c(b), X L(c)$ of the fourth expanded leaf of the first branch of $B$. papyrifera grown in the agricultural soils and champing force $(F)$

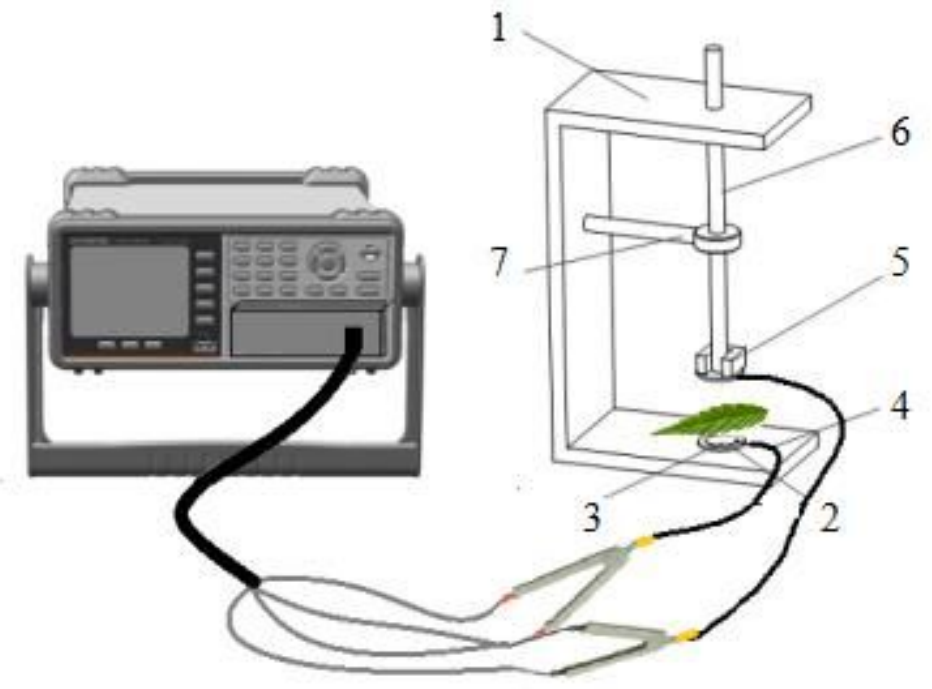

Figure 3 
The experimental setup used in the study and a schematic diagram of the parallel-plate capacitor. $1=$ holder (315 mm of height), $2=$ cystosepiment (32 $\mathrm{mm}$ of diameter), $3=$ plate electrode $(7 \mathrm{~mm}$ of diameter), $4=$ electrical conductor, $5=$ iron block, $6=$ plastic $\operatorname{rod}(295 \mathrm{~mm}$ of height), $7=$ bench holdfast (130 mm of length).

\section{Supplementary Files}

This is a list of supplementary files associated with this preprint. Click to download.

- 12.RawData.xlsx

- 11.Additionalfile1.docx 